\title{
Assessment of Genetic Diversity among Pleurotus spp. Isolates from Jordan
}

\author{
Hanan Aref Hasan ${ }^{1}$, Ahmad Mohamad Almomany ${ }^{2}$, Shireen Hasan ${ }^{3}$ and \\ Ayed M. Al-Abdallat ${ }^{4, *}$ \\ 1 Department of Plant Production and Protection, Faculty of Agriculture, Jeresh University, \\ Jeresh 26150, Jordan; jarunih@yahoo.com \\ 2 Department of Plant Protection, Faculty of Agriculture, The University of Jordan, Amman 11942, Jordan; \\ momanyah@ju.edu.jo \\ 3 Hamdi Mango Center for Scientific Research, The University of Jordan, Amman 11942, Jordan; \\ s.hasan@ju.edu.jo \\ 4 Department of Horticulture and Crop science, Faculty of Agriculture, The University of Jordan, \\ Amman 11942, Jordan \\ * Correspondence: a.alabdallat@ju.edu.jo; Tel.: +962-7721-85555 (ext. 22331)
}

Received: 16 February 2018; Accepted: 25 April 2018; Published: 29 April 2018

\begin{abstract}
Pleurotus is considered an important genus that belongs to the family Pleurotaceae and includes the edible King Oyster mushroom (Pleurotus eryngii). In the present study, 19 Pleurotus isolates were collected from two locations in the north of Jordan (Tell ar-Rumman and Um-Qais). The morphological characteristics among collected isolates revealed that there was a morphological similarity among the collected isolates. Nucleotide sequence analysis of the internal transcribed spacer (ITS1-5.8S rDNA-ITS4 region) and 28S nuclear large subunit (nLSU) in the ribosomal DNA gene of the isolated stains showed that all of them share over $98 \%$ sequence similarity with P. eryngii. Genetic diversity among the collected strains was assessed using inter simple sequence repeat (ISSR) analysis using 18 different primer pairs. Using this approach, 141 out of 196 bands obtained were considered polymorphic and the highest percentage of polymorphism was observed using primer UBC827 (92.3\%) with an overall Polymorphism Information Content (PIC) value of 70.56\%. Cluster analysis showed that the Jordanian Pleurotus isolates fall into two main clades with a coefficient of similarity values ranging from 0.59 to 0.74 with a clear clustering based on collection sites. The results of the present study reveal that molecular techniques of ISSR and rDNA sequencing can greatly aid in classification and identification of Pleurotus spp. in Jordan.
\end{abstract}

Keywords: Pleurotus; mushroom; inter simple sequence repeat (ISSR); internal transcribed spacer region; genetic diversity

\section{Introduction}

Pleurotus eryngii or King Oyster mushroom is a tetra-polar heterothallic edible fungus, which can form an edible fruiting body on lignocellulosic substrates [1]. It belongs to the phylum Basidiomycota, class Agaricomycetes, order Agaricales, family Pleurotaceae, genus Pleurotus [2]. This edible mushroom is distributed from central Europe to the northern coast of the Mediterranean Sea, North Africa, Central Asia, Turkey, and Iran [3-5]. P. eryngii is among the most cultivated species of all Pleurotus due to its excellent shape, consistency of cap and stem dimensions, culinary qualities, and its long shelf life [4]. Moreover, P. eryngii has important medicinal properties due to its immune-stimulatory effects and antifungal activity [6,7]. Moreover, it can be used in the degradation of raw plant materials, bioremediation of heavy metal contamination in soil, and bioconversion of organic compounds [8]. 
In nature, there are $~ 1150$ edible and food fungal species available, from which, 40 species belong to Pleurotus [9]. The breeding of new P. eryngii varieties with superior properties, such as high productivity and disease resistance, is still urgently needed. Meanwhile, a drastic loss of genetic diversity in natural populations of Pleurotus is occurring as a consequence of urbanization, domestication, and loss of habitat [10]. Therefore, assessment of genetic diversity among local P. eryngii isolates is crucial for the improvement of $P$. eryngii and future preservation of its valuable germplasm [1]. For this purpose, molecular markers are commonly used for the analysis of genetic diversity and they revealed superiority over conventional traditional methods of classification such as morphological traits and isozymes [11]. For instance, internal transcribed spacer (ITS) regions of the ribosomal RNA genes have been widely used to reconstruct the phylogenetic history of several fungi at the upper and lower levels of relatedness [12-14]. For P. eryngii, RPB2 seems to be more accurate to distinguish varieties [15], but ITS regions are useful to compare new samples to the different known species. Molecular markers are independent of environmental parameters and provide high levels of detectable polymorphism to determine the genetic diversity that can be used as an efficient tool in breeding programs purposes $[16,17]$. Several molecular markers have been used in P. eryngii diversity studies such as Randomly Amplified Polymorphic DNA (RAPD), Inter Simple Sequence Repeat (ISSR), and Sequence Related Amplified Polymorphism (SRAP) [8,17].

The aim of this study was to identify, using morphological and molecular techniques, several Pleurotus spp. Jordanian isolates, collected from two different locations. Molecular identification of the Jordanian Pleurotus isolates was achieved using sequence information of the internal transcribed spacer (ITS1-5.8S-ITS2) and the $28 \mathrm{~S}$ nuclear large subunit (nLSU) in the nuclear ribosomal DNA. Secondly, the genetic diversity among Jordanian Pleurotus isolates was assessed using inter simple sequence repeat (ISSR) markers.

\section{Materials and Methods}

\subsection{Collection and Pure Culture Preparation}

Nineteen Pleurotus isolates were collected in February 2014 from two different locations across Jordan: Tell-ar-Rumman (Latitude: N 32 $16^{\prime} 40^{\prime \prime}$; Longitude: E 35 $83^{\prime} 41^{\prime \prime}$; Altitude: $575 \mathrm{~m}$ ) and Um-Qais (Latitude: N 32 $65^{\prime} 35^{\prime \prime}$; Longitude: E $35^{\circ} 68^{\prime} 54^{\prime \prime}$; Altitude: $252 \mathrm{~m}$ ). The two locations were selected as they are parts of the Mediterranean climatic zone in Jordan where forest and vegetation cover exist, which represent a natural habitat for Pleurotus. The isolates were collected in valleys behind streams of water very close to rivers; Tell-ar-Rumman isolates were near the Zaraqa River and Um-Qais isolates were near the Jordan River. Such areas are known to have suitable humidity, sufficient rainfall, fertile soil, and temperatures to promote Pleurotus growth. The isolates were collected behind Umbelliferae plants; Um-Qais isolates were found only on Ferula armandii, while, in Tell-Rumman, the first 7 samples were found on Ferula armandii and the last three were found on Daucus carota subsp. sativus.

Pure mycelium colonies from the collected Pleurotus isolates were obtained by two methods: spore print and from mushroom tissue. The fruit body of the collected Pleurotus was cleaned from any plant and soil debris, then it was dried well on white filter paper for $24 \mathrm{~h}$. The next day, spores were isolated with a sterile needle and then inoculated into Potato Dextrose Agar (PDA) sterile autoclaved media. Another method used to obtain mycelium was by cutting the collected mushroom bodies into very thin small pieces that include the cap, gills, and the stem of the strain. Then, these small cut pieces were moved gently into a clean petri dish with sterile water to clean them from any soil and plant debris, and were then transferred into another washing petri dish with $0.5 \%$ sodium hypochlorite for $3 \mathrm{~min}$ where they were removed gently and washed in sterile water. After that the washed pieces were dried on white filter paper and used to inoculate PDA autoclaved media to get the necessary mycelia colony of Pleurotus spp. After four days of incubation, newly emerging mycelia was used to establish a pure culture on PDA media, which was maintained at $25^{\circ} \mathrm{C}$ in the dark. For storage, new emerging mycelia was picked and transferred to PDA media and kept at $4{ }^{\circ} \mathrm{C}$ in the refrigerator. 


\subsection{Morphological Characterization}

For morphological characterization, each isolate was studied in the laboratory by taking measurements of the cap (shape, size, color), and the texture (smooth, fibrous, sticky, and scaly), stem (height, diameter, color and texture (ring, volva, basal bulb, and roots), gills (color, shape, and attachment to stem), flesh (color, texture, exude milk, smell and taste), spore (color, shape, spore print, and measurements of length and width). The procedures for morphological descriptions were followed according to $[18,19]$, and by using the Fungal Databases Nomenclature and species Banks, and by referring to https:/ / www.mushroomthejournal.com.

Spore print for each fresh mature sample was also defined by laying the fruiting body over glass sheath and by covering it overnight with a beaker to avoid drying. Spores of each mushroom body were microscopically (Labphoto, Nikon, Tokyo, Japan) investigated and photographed recording the shape, color, and size as described in [20].

\subsection{Dna Extraction}

Total Genomic DNA was extracted from young, healthy and fresh stem and cap tissue samples from collected fruiting bodies using E.Z.N.A. ${ }^{\circledR}$ SP Fungal DNA Mini Kit (Omega Bio-tek, Inc., Norcross, GA, USA) following the manufacturer's instruction. The DNA quality was assessed by gel electrophoresis in a $1 \%$ agarose gel stained with Red Safe (Intron, Bio-tek, Seoul, Korea). DNA concentration was determined using a spectrophotometer (BIO-RAD, Smart $\operatorname{spec}^{\mathrm{Tm}}$ plus spectrophotometer, Hercules, CA, USA) and stock solution $(30 \mathrm{ng} / \mu \mathrm{L})$ for each isolate was prepared with sterile distilled water and then stored at $-20{ }^{\circ} \mathrm{C}$ for PCR reaction.

\subsection{ITS and Nlsu Amplification and Sequence Analysis}

For the amplification of the ITS region, the ITS1 forward (5'-TCCGTAGGTGAACCTGCGG-3') and ITS4 reverse primers ( $5^{\prime}$-TCCTCCGCTTATTGATATGC- $\left.3^{\prime}\right)$ were used as described previously [21]. For the amplification of the nLSU region, the LR0R (5'-ACCCGCTGAACTTAAGC- $\left.3^{\prime}\right)$ and LR16 (5'-TTCCACCCAAACACTCG-3') were used as described previously [22]. The PCR amplification was carried out in a $25 \mu \mathrm{L}$ total volume reaction consisting of $12.5 \mu \mathrm{L}$ PCR master mix (Intron, Bio-tek, Seoul, Korea), $1.25 \mu \mathrm{L}$ of 10 pmol of both primers, $2.5 \mu \mathrm{L}$ of template DNA from the stock $(30 \mathrm{ng} / \mu \mathrm{L})$, and $7.5 \mu \mathrm{L}$ nuclease- free water. The PCR program conditions were as follows: $94{ }^{\circ} \mathrm{C}$ for $5 \mathrm{~min}$ for initial genomic DNA denaturation, 40 cycles of $94{ }^{\circ} \mathrm{C}$ for $40 \mathrm{~s}, 55^{\circ} \mathrm{C}$ for $30 \mathrm{~s}$, and $72{ }^{\circ} \mathrm{C}$ for $1 \mathrm{~min}$, and a final elongation step at $72{ }^{\circ} \mathrm{C}$ for $5 \mathrm{~min}$. The amplified products were purified using E.Z.N.A Gel Extraction Kit-Spin (Omega Bio-tek, Inc., Norcross, GA, USA), following the manufacturer's instructions, and the products were analyzed to test the integrity and concentration on $1.5 \%$ agarose gel using electrophoresis.

PCR products were directly sequenced from both directions using the same primers used for the amplification. Final cleaned PCR products were sent to Macrogene Inc. (Seoul, Korea) and were sequenced using an ABI 3730XL capillary electrophoresis sequencing station (Applied Biosystem, Foster City, CA, USA). For molecular identification, the obtained DNA sequences from the Jordanian isolates were used as a query in a BLASTn (http:/ /blast.ncbi.nlm.nih.gov) search against the GenBank nr DNA sequences database as described previously [23]. DNA sequences of the Jordanian isolates were deposited in the GenBank under PopSet: 1374951795 (Accession numbers: MH168609.1 MH168630.1).

Phylogenetic analysis was carried out using MEGA 6 software [24]. The ITS sequences of the 19 Pleurotus isolates from this study was used, together with previously published ITS Pleurotus spp. reference sequences, including P. eryngii (EU395845.1), P. eryngii var. ferulae (AB286152.1), P. nebrodensis (AB286148), P. eryngii var. tuoliensis (AB286164.1), P. ostreatus (AY450345), and P. cystidiosus (AY315766). The sequences were aligned using the Muscle algorithm and used to build a phylogenetic tree by calculating distance matrices for neighbor-joining analysis with the Kimura two-parameter model and bootstrapping analysis with 10,000 replicates to test the robustness of the internal branches. 


\subsection{Issr Analysis}

Eighteen ISSR primers were selected and used in this study based on sequence information described in $[8,17]$. The ISSR amplifications were carried out in a $25 \mu \mathrm{L}$ reaction containing $2.5 \mu \mathrm{L}$ of $30 \mathrm{ng}$ DNA template, $0.25 \mu \mathrm{L}$ primer (10 pmol), $12.5 \mu \mathrm{L}$ master mix (Intron, Bio-tek, Seoul, Korea), and nuclease-free water. Amplification conditions were as follows: an initial denaturation at $94{ }^{\circ} \mathrm{C}$ for $5 \mathrm{~min}$, followed by 35 cycles each at $94{ }^{\circ} \mathrm{C}$ for $30 \mathrm{~s}, 41^{\circ} \mathrm{C}$ for $45 \mathrm{~s}$, and $72{ }^{\circ} \mathrm{C}$ for $90 \mathrm{~s}$, followed by a final extension for $7 \mathrm{~min}$ at $72{ }^{\circ} \mathrm{C}[8,17]$. The PCR products were visualized using $2 \%$ agarose gel using a high resolution gel electrophoresis, (Elchrom Scientific Ag, Cham, Switzerland) stained with red safe dye (Intron, Bio-tek, Seoul, Korea). The ISSR analysis was repeated three times for each sample and only reproducible bands in the three replicates were used in further analysis.

For genetic diversity assessment, each ISSR reproducible band was scored and transformed into a binary matrix where the presence of a reproducible polymorphic DNA band at a particular position (obtained from three technical replicates) on the gels was scored as 1 , while 0 means its absence. The collected marker data was used to generate a distance matrix using the Numerical Taxonomy Multivariate Analysis System (NTSys-PC applied Biostatics, version 2.02) [25], a program based on the Dice similarity coefficient [26]. A dendrogram was generated based on the UPGMA algorithm (Un-weighted pair group method with arithmetic average) as described previously [8].

\section{Results}

\subsection{Morphological Characteristics of Jordanian Pleurotus Isolates}

All collected Pleurotus isolates from the two locations were examined macroscopically and microscopically and their morphological characteristics were recorded depending on descriptors available for P. eryngii (Figure 1 and Table 1). The characteristics among the collected Pleurotus isolates from the same location revealed that there are variations at the morphological level (Table 1). There were differences between cap color and diameter among isolates collected from the two habitats and in some instances within the same location (Table 1). For instance, the stem shape was different between collected isolates from the two locations; it was thick cylindrical in Tell ar-Rumman samples, while it was thick and eccentric in the Um-Qais samples (Table 1). Also, clear differences were obtained in gills color of different isolates; it was whitish honey in the Tell ar-Rumman samples but it was greyish to white in the Um-Qais sample sites. Microscopically, the length and width of spore were different among isolates per habitat. For instance, Tell ar-Rumman samples had the largest spores' length (range between 5 and $10 \mu \mathrm{m}$ ) and width (range between 2 and $5 \mu \mathrm{m}$ ) when compared to samples from Um-Qais (Table 1).

\section{A}

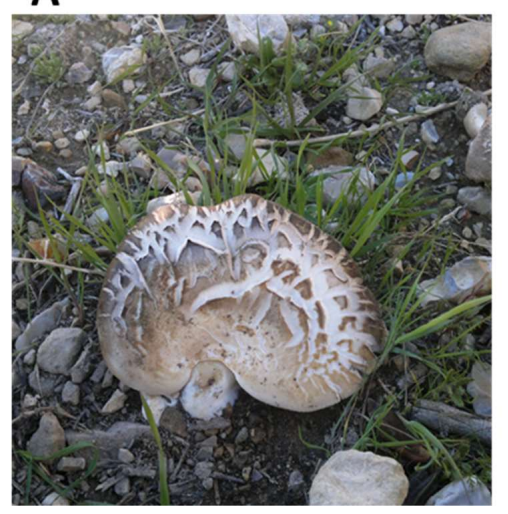

B

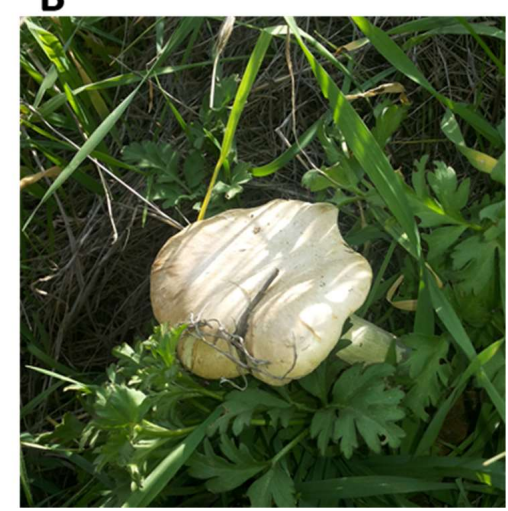

Figure 1. Pleurotus isolates collected from two different natural habitats across Jordan. (A) Tell ar-Rumman; (B) Um-Qais. 
Table 1. Morphological characteristics of mature Pleurotus Mushroom's Fruit Bodies and spores collected naturally from two different locations across Jordan.

\begin{tabular}{|c|c|c|c|}
\hline Item & Description & Um-Qais & Tell ar-Rumman \\
\hline \multirow{3}{*}{ Cap } & Color & White, gray to beige & Flesh white to grey brown \\
\hline & Shape & Funnel shaped and irregular & Funnel shaped and irregular \\
\hline & Diameter & $3-9 \mathrm{~cm}$ & $4-9 \mathrm{~cm}$ \\
\hline \multirow{3}{*}{ Stem } & Color & Flesh white & White to brown \\
\hline & Shape & Eccentric thick, cylinder shape & Thick cylindrical \\
\hline & Dimensions & Height:1-4 cm; Diameter: $1 \mathrm{~cm}$ & Height:1-4 cm; Diameter: $1 \mathrm{~cm}$ \\
\hline \multirow{4}{*}{ Spore } & Color & White, creamy to yellow & White, creamy to yellow \\
\hline & Shape & Elliptic narrow; cylinder shape & Elliptic narrow, cylinder shape \\
\hline & Print & White & White \\
\hline & Measurements & Length: $5-7 \mu \mathrm{m}$; Width: $2-3 \mu \mathrm{m}$ & Length: $5-10 \mu \mathrm{m}$; Width: $2-5 \mu \mathrm{m}$ \\
\hline \multirow{3}{*}{ Gills } & Color & Greyish & Whitish honey \\
\hline & Shape & Long extended internally to stem & Long extended internally to stem \\
\hline & Attachment & Descending with stem & Descending with stem \\
\hline Flesh & Color and smell & White with taste and smell pleasant & White with taste and smell pleasant \\
\hline
\end{tabular}

\subsection{Molecular Identification Using ITS Analysis}

For ITS and nLSU sequence analysis, the amplification products from different Pleurotus isolates gave band size around $600 \mathrm{bp}$ and in all cases a single sharp band was produced that was used for direct sequencing. The partial ITS and nLSU nucleotide sequences of the 19 Pleurotus isolates were obtained and analyzed for sequence similarity in the GenBank using the blastn tool (Table 2). All collected isolates produced high sequence similarity percentage (above 98\%) against nLSU sequences from previously deposited sequences of P. eryngii. All collected isolates produced high sequence similarity percentage (above 97\%) against ITS sequences from previously deposited P. eryngii sequences. Phylogenetic analysis with ITS sequences of the 19 isolates with high similarity to P. eryngii with different Pleurotus spp. reference sequences confirmed the identification of the collected isolates within the P. eryngii var. erygnii-ferulae complex [27] (Figure 2).

Table 2. Molecular identification of 19 Jordanian Pleurotus isolates using internal transcribed spacer (ITS) and nuclear large subunit (nLSU) rRNA sequence analysis.

\begin{tabular}{|c|c|c|c|c|c|c|c|}
\hline \multicolumn{2}{|c|}{ Isolates } & \multicolumn{3}{|c|}{ Best nr Database Similarity Hit Using nLSU } & \multicolumn{3}{|c|}{ Best nr Database Similarity Hit Using ITS } \\
\hline No & Code * & Taxon & ID $\%$ & GenBank Accession No. & Taxon & ID \% & GenBank Accession No. \\
\hline 1 & Q1 & P. eryngii & 98 & KY963032.1 & P. eryngii var. ferulae & 99 & KY962437.1 \\
\hline 2 & Q2 & P. eryngii & 99 & AB777519.1 & P. eryngii & 97 & KY962448.1 \\
\hline 3 & Q3 & P. eryngii & 99 & AY450347.1 & P. eryngii & 99 & KX977448.1.1 \\
\hline 4 & $\widehat{\mathrm{Q}} 4$ & P. eryngii & 100 & AB777519.1 & P. eryngii & 99 & MG282489.1 \\
\hline 5 & Q5 & P. eryngii & 99 & AY450347.1 & P. eryngii var. ferulae & 99 & MG282459.1 \\
\hline 6 & $\widehat{\mathrm{Q} 6}$ & P. eryngii & 99 & AY450347.1 & P. eryngii & 97 & KX977448.1 \\
\hline 7 & Q7 & P. eryngii & 99 & AB777519.1 & P. eryngii & 99 & MG282489.1 \\
\hline 8 & Q8 & P. eryngii & 99 & KY963084.1 & P. eryngii & 99 & KX977448.1 \\
\hline 9 & Q9 & P. eryngii & 99 & KY963084.1 & P. eryngii & 98 & JX429941.1 \\
\hline 10 & R1 & P. eryngii & 99 & AB777519.1 & P. eryngii & 100 & MG282489.1 \\
\hline 11 & $\mathbf{R} 2$ & P. eryngii & 99 & AB777519.1 & P. eryngii & 99 & MG282489.1 \\
\hline 12 & R3 & P. eryngii & 99 & MG282549.1 & P. eryngii & 100 & MG282489.1 \\
\hline 13 & R4 & P. eryngii & 99 & MG282549.1 & P. eryngii & 99 & KX836359.1 \\
\hline 14 & R5 & P. eryngii & 99 & MG282549.1 & P. eryngii & 98 & MG282489.1 \\
\hline 15 & R6 & P. eryngii & 99 & MG282549.1 & P. eryngii & 99 & MG282489.1 \\
\hline 16 & R7 & P. eryngii & 98 & MG282549.1 & P. eryngii & 99 & MG282489.1 \\
\hline 17 & R8 & P. eryngii & 98 & MG282549.1 & P. eryngii & 99 & MG282489.1 \\
\hline 18 & R9 & P. eryngii & 99 & MG282549.1 & P. eryngii & 99 & MG282489.1 \\
\hline 19 & R10 & P. eryngii & 99 & MG282549.1 & P. eryngii & 99 & MG282489.1 \\
\hline
\end{tabular}

* Location codes: (Q) Um-Qais; (R) Tell ar-Rumman. 


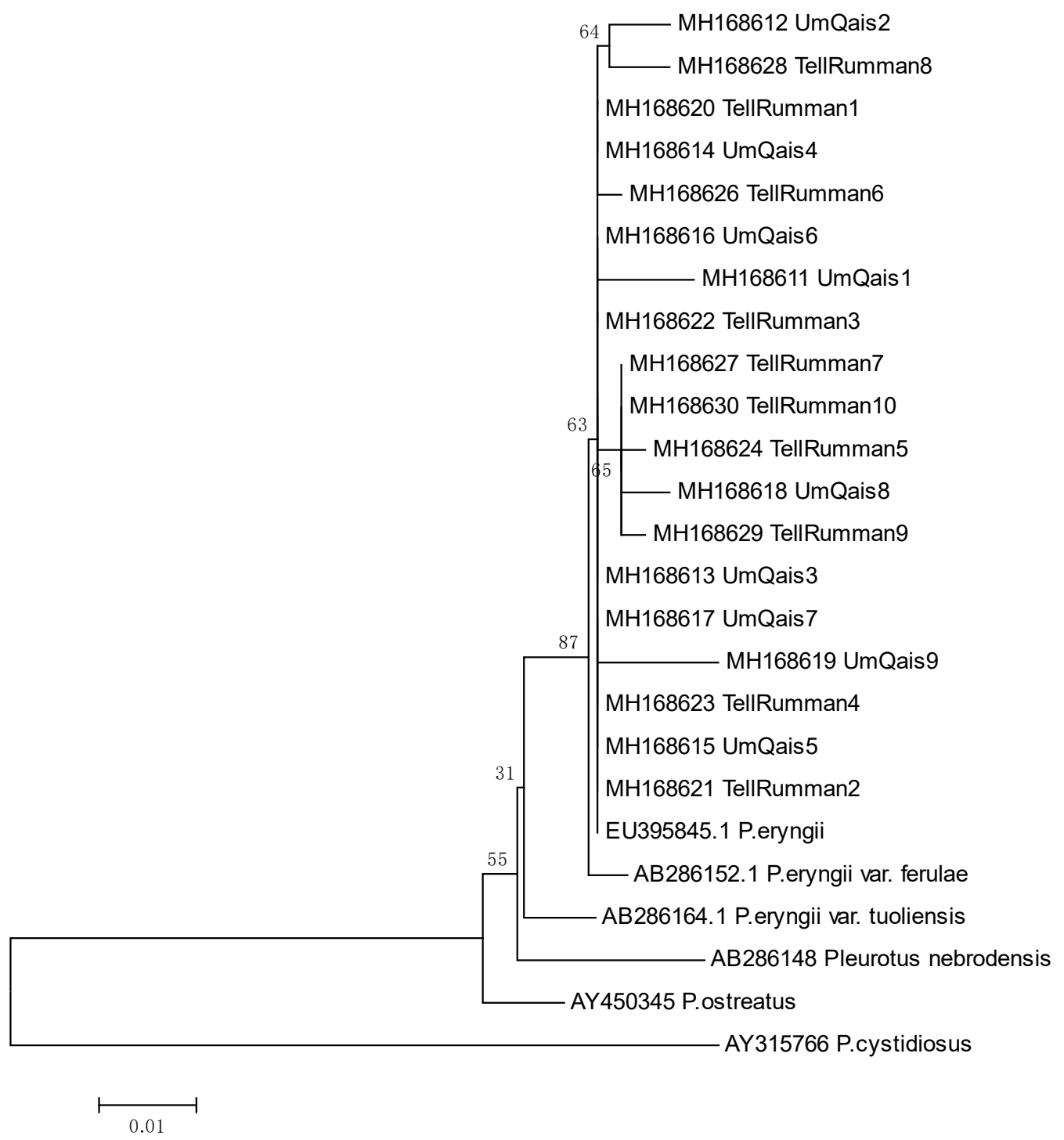

Figure 2. Phylogenetic tree using neighbor-joining analysis between 19 Pleurotus Jordanian isolates collected from two locations (Um-Qais and Tell ar-Rumman) based on ITS sequences and selected reference sequences (GenBank accession number for collected isolates and reference strains are given before the isolate name).

\subsection{Genetic Diversity by Using ISSR}

Eighteen ISSR primers previously tested on Pleurotus isolates from different regions $[8,28]$ were used to assess genetic diversity among the Jordanian isolates (Figure 3; Table 3). Seventeen ISSR primers gave reproducible results in at least three independent reactions as shown in Table 3. The UBC811 failed to produce any PCR products and was discarded from further analysis. From the total number of bands obtained and the percentages of polymorphisms of each tested primer, 141 out of 196 bands were considered polymorphic, generating a PIC overall average of $70.56 \%$. The maximum percentage of polymorphism was observed using primer UBC827 (92.3\%), while the lowest percentage was observed using primer UBC809 (6.6\%).

The molecular data was used to build a dendrogram based on Dice's coefficient of similarity to assess the genetic relatedness between the collected 19 Pleurotus isolates (Figure 4). The genetic similarity among the 19 isolates ranged from $59 \%$ to $74 \%$, indicating the existence of high genetic diversity between them and a clear clustering based on collection site was observed. At the Tell 
ar-Rumman location, isolates \#2 and \#3 were closely related to each other, while, at Um Qais location, isolates \#5 and \#7 were also closely related to each other in the second clade. Percentage of polymorphism among 19 isolates of Pleurotus, obtained by ISSR markers was high enough to discriminate the isolates according to their collection site in Jordan.
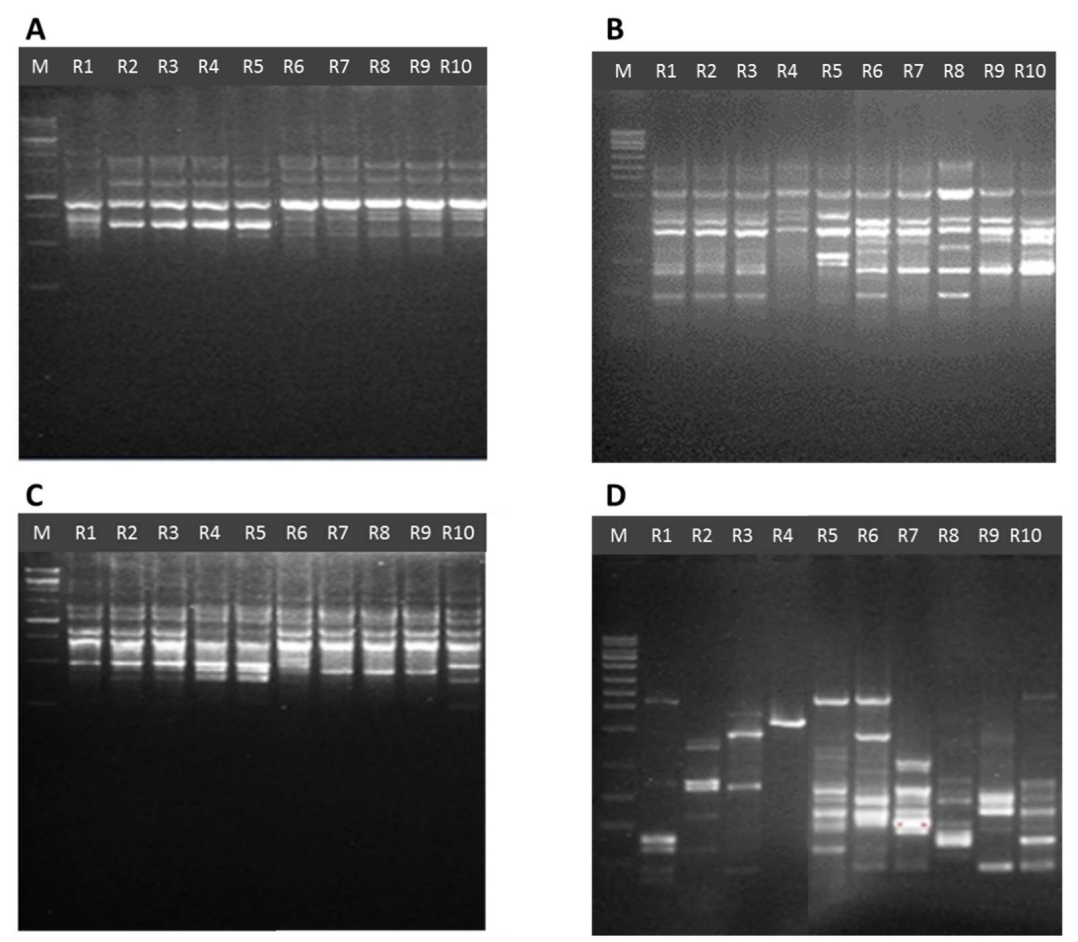

Figure 3. Representative inter simple sequence repeat (ISSR) profiles in 11 Pleurotus Jordanian isolates from the Tell ar-Rumman location. (A) UBC866; (B) UBC864; (C) UBC809; (D) UBC823; M: 1 Kb Ladder (Gene Direx, Keelung City, Taiwan).

Table 3. ISSR markers analysis and polymorphism in 19 Jordanian Pleurotus isolates.

\begin{tabular}{|c|c|c|c|c|}
\hline Primer & Sequences & Total Bands & $\begin{array}{l}\text { Polymorphic } \\
\text { Bands }\end{array}$ & PIC (\%) \\
\hline UBC807 & $(\mathrm{AG}) 8 \mathrm{~T}$ & 14 & 10 & 71.4 \\
\hline UBC 808 & (AG)8C & 11 & 9 & 81.8 \\
\hline UBC 809 & (AG)8G & 15 & 1 & 6.66 \\
\hline UBC810 & $(\mathrm{GA}) 8 \mathrm{~T}$ & 12 & 9 & 75 \\
\hline UBC811 & $(\mathrm{GA}) 8 \mathrm{C}$ & 0 & 0 & 0 \\
\hline UBC 812 & (GA) $8 \mathrm{~A}$ & 11 & 10 & 90.9 \\
\hline UBC816 & (CA)8T & 11 & 8 & 72.7 \\
\hline UBC 823 & (TC) $8 \mathrm{C}$ & 16 & 13 & 81.2 \\
\hline UBC825 & $(\mathrm{AC}) 8 \mathrm{~T}$ & 12 & 11 & 91.6 \\
\hline UBC826 & $(\mathrm{AC}) 8 \mathrm{C}$ & 12 & 8 & 66.6 \\
\hline UBC827 & (AC) $8 \mathrm{G}$ & 13 & 12 & 92.3 \\
\hline UBC864 & (ATG) 5 & 9 & 7 & 77.7 \\
\hline UBC866 & (CTC) 6 & 8 & 5 & 62.5 \\
\hline UBC868 & (GAA)6 & 9 & 8 & 88.8 \\
\hline UBC873 & (GACA)4 & 7 & 4 & 57.1 \\
\hline UBC874 & $(\mathrm{CCCT}) 4$ & 9 & 8 & 88.8 \\
\hline UBC876 & (GATA)2(GACA)2 & 12 & 11 & 91.66 \\
\hline UBC880 & (GGAGA)3 & 15 & 11 & 73.3 \\
\hline Total & & 196 & 141 & \\
\hline Mean & & 10.89 & 7.83 & 70.56 \\
\hline
\end{tabular}




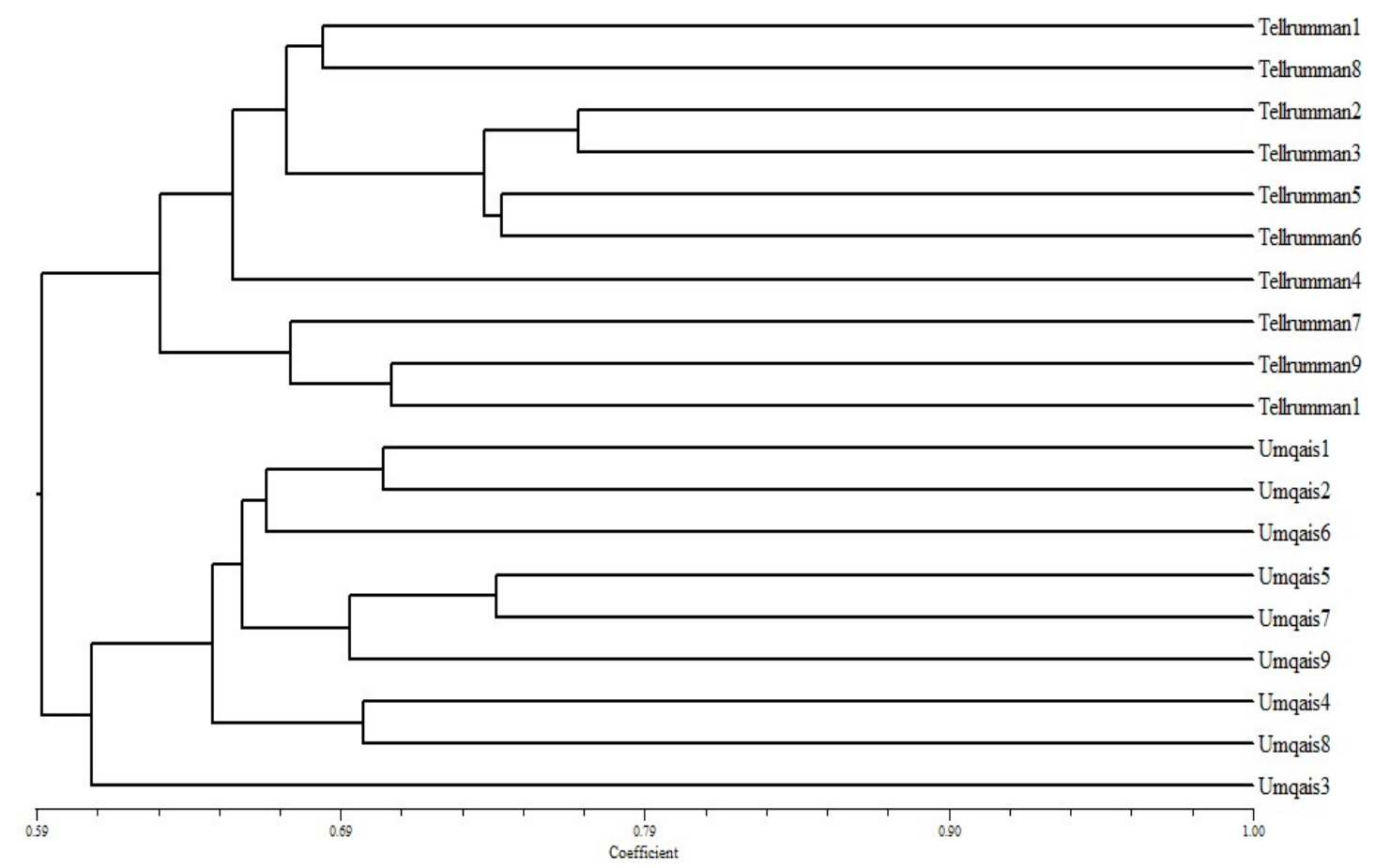

Figure 4. A dendrogram showing relationships among 19 Jordanian Pleurotus isolates by using ISSR markers data and the Dice genetic similarity and the Un-weighted pair group method with arithmetic average (UPGMA) clustering method.

\section{Discussion}

In this study, 19 collected Jordanian Pleurotus isolates from two different habitats were examined for their morphological characteristics and their identities were analyzed by using different molecular markers. Sequence comparison of the ITS and nLSU regions is widely used in taxonomy and molecular phylogeny of fungi because it is easy to amplify even from small quantities of DNA due to the high copy number of rDNA genes with a high degree of variation even between closely related species [22,29]. In this study, the amplification of ITS regions from different Jordanian isolates gave band sizes of around $600 \mathrm{bp}$; this is in general agreement with Imtiaj et al. [13], who found that the ITS amplified products from Pleurotus isolates collected from different geographical regions showed minor differences in size. On the other hand, differences in sizes of ITS amplified products are considered a useful tool to discriminate between Pleurotus spp. collected from different geographical regions. For instance, a maximum length of ITS amplified products was recorded in P. djamor (667 bp), whereas the minimum length was recorded in P. ferulae (571 bp) [30]. P. nebrodensis, P. eryngii, and P. cornucopiae produced identical sizes for ITS products ( $639 \mathrm{bp}$ ) but still the nucleotide sequences were different. The sequence analysis of ITS and nLSU regions in the 19 Jordanian Pleurotus isolates showed that all collected isolates produced high similarity percentages (above 97\%) with ITS and nLSU sequences from P. eryngii. Phylogenetic analysis confirmed that the 19 Jordanian Pleurotus isolates grouped with P. eryngii var. erygnii-ferulae confirming their identity within the complex [27] (Figure 2). However, caution should be considered in interpreting rDNA sequence data analysis as closely related Pleurotus spp. could not be distinguished by ITS analysis alone and further sequence analysis using other nuclear genes such as $\beta$-tubulin, RPB2, and EF1 $\alpha$ might be needed [31-33]. For instance, sequence variations in EF1- $\alpha$ gene were able to discriminate the P. nebrodensis from China and Sicily from P. eryngii-ferulae from the Mediterranean region [33].

In this study, the 19 Jordanian strains showed high levels of genetic diversity as revealed by using ISSR markers. The PIC percentages were considerably high, which is in agreement with previous findings $[8,29]$. For instance, the genetic diversity in 15 Chinese P. pulmonarius by using 20 ISSR primers 
generated 283 bands from which 211 were polymorphic $(74.6 \%)$, which is in agreement with our findings [8]. In another study, Prasad and Agarwal [7] used SSR and ISSR markers for discrimination between different commercial mushroom samples (A. bisporus; P. eryngii; L. edodes; H. tessellatus; $P$. ostreatus and P. diamor), and ISSR markers were found to be powerful in discriminating between mushroom species. RAPD and ISSR were found to be more useful in distinguishing P. eryngii isolates and varieties for mushroom breeding programs $[15,28]$. For instance, RAPD analysis was used to assess the genetic diversity among 45 Pleurotus strains collected from five different host-plants in Iran, which resulted in clustering the isolates based on their host-plants [34]. The ISSR markers used in this study were used previously to assess genetic diversity among $32 \mathrm{H}$. marmoreus isolates from different locations in China [28]. The average number of amplified bands per primer was 11.0 and the polymorphism information content was $87.4 \%$, indicating a high level of polymorphism among the tested markers, which is the case with our findings. The proportion of polymorphic bands ranged from $52.9 \%$ (primer UBC899) to 100\% (primers UBC823, UBC824, UBC840, UBC841, UBC842, and UBC900), with an average of $87.46 \%$. In another study, Ravash et al. [34], used ISSR and ScoT markers to evaluate the genetic diversity of the wild mushroom (P. eryngii var. tuoliensis) and they concluded that a high level of genetic polymorphism $(96.3 \%)$ exists. Similar results were obtained with other edible species such as Lentinula edodes (99.6\%) [35] and Auricularia polytricha (99.8\%) [36]. In contrast, Yin et al. [17] found that RAPD markers were the best in differentiation of 15 P. pulmonarius isolates in China, with a polymorphic percentage of $79.5 \%$ as compared to $74.6 \%$ using ISSR and $74.8 \%$ by using SRAP marker.

In this study, NTSys analysis indicates an association of collected isolates to their geographical distribution and collection sites (Figure 4). Such results were observed in wild P. eryngii var. tuoliensis from china where a clear clustering of collected isolates was obtained [37]. The geographic distribution among the two habitats in Jordan is clearly obvious where a clear difference in altitude, climate, and rainfall exist. In addition, the degree of differentiation between populations may be affected by many factors such as gene flow, genetic drift, and geographical distribution [33]. However, clear genetic variations exist between collected isolates within each site. Furthermore, the samples that were distinctly less similar with P. eryngii in ITS and nLSU sequence analysis didn't form any outgroup as expected and clustered with isolates from the same location. This might be explained that higher levels of gene flow might lead to less variation among local populations. For instance, longitudinal differences between different habitats played an important role in the degree of polymorphism among P. eryngii isolates in Israel [38].

\section{Conclusions}

In this study, the morphological characterization of 19 Jordanian Pleurotus isolates collected from two different sites indicate differences in cap color and diameter, gills color, shape of the stem, and spore measurements. Molecular identification of the Jordanian isolates using ITS and nLSU sequence analysis demonstrated that the majority of them share high sequence similarity with $P$. eryngii. ISSR markers used in this study generated high PIC values indicating the existence of a high degree of genetic diversity among Pleurotus isolates. Phylogenetic analysis revealed a clear association with geographical distribution and collection sites. In future, selection for suitable techniques for a large scale production and commercialization accompanied with breeding strategies with strains of other related populations is needed for king oyster mushroom in Jordan.

Author Contributions: H.A.H. conceived most of the research and experimental work, and drafted the manuscript. A.M.A. conceived the research and helped in material collection and isolation. S.H. helped in experimental work and NTSys analysis. A.M.A.-A. conceived the research and helped in molecular and bioinformatics analysis.

Acknowledgments: The authors would like to thank the Deanship of Scientific Research, The University of Jordan (Amman, Jordan) for their financial support.

Conflicts of Interest: The authors declare no conflict of interest. 


\section{Abbreviations}

$\begin{array}{ll}\text { BLAST } & \text { Basic Local Alignment Search Tool } \\ \text { ISSR } & \text { Inter simple short repeat } \\ \text { ITS } & \text { Inter transcribed spacer } \\ \text { PDA } & \text { Potato dextrose Agar } \\ \text { BlASTn } & \text { nucleotide-nucleotide blast } \\ \text { NTSys } & \text { Numerical Taxonomy Multivariate Analysis System } \\ \text { PIC } & \text { Polymorphism Information Content } \\ \text { UPGMA } & \text { Unweighted Pair Group Method with Average }\end{array}$

\section{References}

1. Alam, N.; Shim, M.J.; Lee, M.W.; Shin, P.G.; Yoo, Y.B.; Lee, T.S. Vegetative Growth and Phylogenetic Relationship of Commercially Cultivated Strains of Pleurotus eryngii based on ITS sequence and RAPD. MYCO 2009, 37, 258-266.

2. Hassan, F.R.; Medany, G.M.; Abou Hussein, S.D. Cultivation of the King Oyster Mushroom (Pleurotus eryngii) in Egypt. Aust. J. Basic Appl. Sci. 2010, 4, 99-105.

3. Rodriguez Estrada, A.E.; Royse, D.J. Yield, size and bacterial blotch resistance of Pleurotus eryngii grown on cotton seed hulls/oak sawdust supplemented with manganese, copper and whole ground soybean. Bioresour. Technol. 2007, 98, 1898-1906. [CrossRef] [PubMed]

4. Behnamian, M.; Mohammadi, S.A.; Sonnenberg, A.; Goltapeh, E.M.; Alavi, A.; Hendrickx, P. Genetic diversity and population structure of Iranian wild Pleurotus eryngii species-complex strains revealed by URP-PCR markers. J. Food Agric. Environ. 2010, 8, 1203-1207.

5. Choi, U.K.; Lee, O.H.; Kim, Y.C. Effect of Calcinated Oyster Shell Powder on Growth, Yield, Spawn Run, and Primordial Formation of King Oyster Mushroom (Pleurotus eryngii). Molecules 2011, 16, 2313-2322. [CrossRef] [PubMed]

6. Ola, I.O.; Unni, B.G.; Oloke, J.K.; Bordoloi, A.K. Morphological, ultrastructural and molecular variability studies of wild and mutant strains of edible Pleurotus species using growth yield, scanning electron microscopy and random amplified polymorphic DNA polymerase chain reaction (RAPD-PCR). Afr. J. Micro Res. 2013, 7, 5057-5065. [CrossRef]

7. Prasad, M.P.; Agarwal, K. DNA fingerprinting of commercial mushrooms by ISSR and SSR markers for genetic determination. Int. J. Pharma Bio Sci. 2013, 4, 1243-1249.

8. Wang, S.; Yin, Y.; Liu, Y. Evaluation of Genetic diversity among Chinese Pleurotus eryngii cultivars by combined RAPD/ISSR marker. Curr. Microbiol. 2012, 65, 424-431. [CrossRef] [PubMed]

9. Boa, E.R. Wild Edible Fungi: A Global Overview of Their Use and Importance to People; Food and Agriculture Organization of the United Nations (FAO): Roma, Italy, 2004; p. 147.

10. Urbanelli, S.; Della Rosa, V.; Punelli, F.; Porreta, D.; Reverberi, M.; Fabbri, A.A.; Fanelli, C. DNAfingerprinting (AFLP and RFLP) for genotypic identification in species of the Pleurotus eryngii complex. Appl. Microbiol. Biotechnol. 2007, 74, 92-600. [CrossRef] [PubMed]

11. Chandra, S.; Ghosh, K.; Acharya, K. Comparative study on the Indian cultivated Pleurotus species by RAPD fingerprinting. Nat. Sci. 2010, 8, 90-94.

12. Bellemain, E.; Carlsen, T.; Brochmann, C.; Coisacc, E.; Taberlet, P.; Kauserud, H. ITS as an environmental DNA barcode for fungi: An in silico approach reveals potential PCR biases. BMC Microbiol. 2010, 10, 189. [CrossRef] [PubMed]

13. Imtiaj, A.; Lee, T.S.; Ohga, S. Sequence variation of Pleurotus species collected from Eastern Asia. Micol. Apl. Int. 2011, 23,1-10.

14. Avin, F.A.; Yee, S.B.; Tan, S.; Shahbazi, P.; Vikineswary, S. Molecular Divergence and Species Delimitation of the Cultivated Oyster Mushrooms: Integration of IGS1 and ITS. Sci. World J. 2014, 2014, 793414. [CrossRef] [PubMed]

15. Rodriguez Estrada, A.E.; Jimenez-Gasco, M.M.; Royse, D.J. Pleurotus eryngii species complex: Sequence analysis and phylogeny based on partial EF1 $\alpha$ and RPB2 genes. Fungal Biol. 2010, 114, 421-428. [CrossRef] [PubMed]

16. Pawlik, A.; Janusz, G.; Koszerny, J.; Małek, W.; Rogalski, J. Genetic diversity of the edible mushroom Pleurotus sp. By amplified fragment length polymorphism. Curr. Microbiol. 2012, 65, 438-445. [PubMed] 
17. Yin, Y.; Liu, Y.; Wang, S.; Zhao, S.; Xu, F. Examining genetic relationships of Chinese Pleurotus ostreatus cultivars by combined RAPD and SRAP markers. Mycoscience 2014, 54, 221-225. [CrossRef]

18. Phillips, R.; Mushrooms, A. Comprehensive Guide with over 1250 Detailed Photographs of Mushrooms and Other Fungi, 1st ed.; Macdonaki, C., Price, P., Eds.; Pan Macmillan: London, UK, 2006.

19. Lincoff, G. The Audubon Society Field Guide to North American Mushrooms; Knopf: New York, NY, USA, 1981.

20. Al-Momany, A.M. Nutritional Aspects of Two Widely Consumed Wild Edible Mushrooms in Jordan. Life Sci. 2013, 7, 653-657.

21. Das, S.K.; Mandal, A.; Datta, A.K.; Gupta, S.; Paul, R.; Saha, A.; Sengupta, S.; Kumari, P. Nucleotide sequencing and identification of some wild mushrooms. Sci. World J. 2013, 2013, 403191. [CrossRef] [PubMed]

22. Junior, N.M.; Asia, T.; Capelari, M.; Meirellus, L.D.P. Morphological and molecular identification of four Brazilian commercial isolates of Pleurotus spp. and cultivation on corncob. Braz. Arch. Biol. Technol. 2010, 53, 397-408. [CrossRef]

23. De Gioia, T.; Sisto, D.; Rana, G.L.; Figliuolo, G. Genetic structure of the Pleurotus eryngii species-complex. Mycol. Res. 2005, 109, 71-80. [CrossRef] [PubMed]

24. Tamura, K.; Stecher, G.; Peterson, D.; Filipski, A.; Kumar, S. MEGA6: Molecular Evolutionary Genetics Analysis version 6.0. Mol. Biol. Evol. 2013, 30, 2725-2729. [CrossRef] [PubMed]

25. Rohlf, F.J. NTSYS-pc: Numerical Taxonomy and Multivariate Analysis System, version 2.02; Exeter Publications: New York, NY, USA, 2000.

26. Dice, L.R. Measures of the amount of ecologic association between species. Ecology 1945, 26, $297-302$. [CrossRef]

27. Kawai, G.; Babasaki, K.; Neda, H. Taxonomic position of a Chinese Pleurotus "Bai-Ling-Gu": It belongs to Pleurotus eryngii (DC.: Fr.) Quél. and evolved independently in China. Mycoscience 2008, 49, 75-87. [CrossRef]

28. Chengshu, Q.; Yan, W.; Li, P.; Deng, W.; Song, B.; Li, T. Evaluation of growth characterstics and genetic diversity of commercial and stored lines of Hypsizygus marmoreus. Int. J. Agric. Biol. 2013, 15, 479-485.

29. Abdulmalk, H.W. Rapid Differentiation of Pleurotus ostreatus from Pleurotus sapidus using PCR Technique. Curr. Res. J. Biol. Sci. 2013, 5, 157-160.

30. Liu, S.; Wu, X.; Liu, X.; Ke, B. Correlation between mating compatibility and the phylogenetic relationship of a rare edible mushroom, Pleurotus nebrodensis, with different Pleurotus species. Int. J. Agric. Biol. 2016, 18, 198-203. [CrossRef]

31. Rodriguez Estrada, A.E.; Royse, D.J.; Jimenez-Gasco, M.M. Nucleotide sequence polymorphisms of the partial b-tubulin gene in two varieties of Pleurotus eryngii. Mushroom Sci. 2008, 17, 83-96.

32. Ro, H.S.; Kim, S.S.; Ryu, J.S.; Jeon, C.O.; Lee, T.S.; Lee, H.S. Comparative studies on the diversity of the edible mushroom Pleurotus eryngii: ITS sequence analysis, RAPD fingerprinting, and physiological characteristics. Mycol. Res. 2007, 111, 710-715. [CrossRef] [PubMed]

33. Mang, S.; Figliuolo, G. Species delimitation in Pleurotus eryngii species-complex inferred from ITS and EF- $1 \alpha$ gene sequences. Mycology 2010, 1, 269-280. [CrossRef]

34. Ravash, R.; Shiran, B.; Alavi, A.; Bayat, F.; Rajaee, S.; Zervakis, G.I. Genetic variability and molecular phylogeny of Pleurotus eryngii species-complex isolates from Iran, and notes on the systematics of Asiatic populations. Mycol. Prog. 2010, 9, 181-194. [CrossRef]

35. Xiao, Y.; Liu, W.; Dai, Y.H.; Fu, C.; Bian, Y.B. Using SSR markers to evaluate the genetic diversity of Lentinula edodes natural germplasm in China. World J. Microbiol. Biotechnol. 2010, 26, 527-536. [CrossRef]

36. Du, P.; Cui, B.K.; Dai, Y.C. High genetic diversity in wild culinary medicinal wood ear mushroom, Auricularia polytricha (Mont) Sacc. in tropical China revealed by ISSR analysis. Int. J. Med. Mushrooms 2011, 13, 289-297. [CrossRef] [PubMed]

37. Zhao, M.; Huang, C.; Chen, Q.; Wu, X.; Qu, J. Genetic Variability and Population Structure of the Mushroom Pleurotus eryngii var. tuoliensis. PLoS ONE 2013, 8, e83253.

38. Lewinsohn, D.; Nevo, E.; Wasser, S.P.; Hadar, Y.; Beharav, A. Genetic diversity in populations of Pleurotus eryngii complex in Israel. Mycol. Res. 2001, 8, 941-951. [CrossRef]

(C) 2018 by the authors. Licensee MDPI, Basel, Switzerland. This article is an open access article distributed under the terms and conditions of the Creative Commons Attribution (CC BY) license (http:// creativecommons.org/licenses/by/4.0/). 